\title{
Persistent sacral nerve root deficits after continuous spinal anaesthesia
}

Randall M. Schell MD, Floyd S. Brauer MD, Daniel J. Cole MD, Richard L. Applegate II MD
Neurological deficits following spinal anaesthesia are rare. We report two cases of persistent sacral nerve root deficits after continuous spinal anaesthesia (CSA) performed with hyperbaric lidocaine through a lumbar microcatheter. In both cases the dose of $5 \%$ lidocaine $(5.7$ and $4.3 \mathrm{ml})$ was greater than usual. In the immediate postoperative period the constellation of neurological deficits included perianal hypaesthesia, lower extremity paresis, urinary retention, and difficult defaecation. Both patients have residual perianal hypaesthesia and difficult defaecation. In these cases, the high-dose requirements of local anaesthetic via microcatheter CSA with focal sensory block suggests nonuniform distribution of the hyperbaric lidocaine. Microcatheter CSA may convey a unique risk of maldistribution of the local anaesthetic solution and local neurotoxicity.

Les déficits neurologiques après l'anaesthésie rachidienne sont rares. On rapporte deux cas de déficit persistant des racines nerveuses sacrées après une anesthésie rachidienne continue (CSA) avec la lidocaine hyperbare à travers un microcatheter lombaire. Dans les deux cas, la dose de lidocaine 5\% (5,7 et 4,3 $\mathrm{ml)}$ était plus grande que d'habitude. Dans la période postopératoire immédiate la constellation de déficits neurologiques ont compris une hypoasthésie périanale, une paresie des membres inférieurs, une rétention urinaire, et une défecation difficile. Les deux patients ont présenté une hypoasthésie périanale résiduelle et une difficulté à la défécation. Dans ces cas, des doses élevées d'anesthésiques locales requises à travers un microcatheter CSA avec blocage sensoriel focal suggère une distribution non uniforme de la lidocaine hyperbare. L'anes-

\section{Key words}

ANAESTHETIC TECHNIQUES: spinal;

ANAESTHETICS, LOCAL: lidocaine; COMPLICATIONS: neurological; NERVE: damage.

From the Department of Anesthesiology, Loma Linda University, Loma Linda, California 92350.

Address correspondence to: Dr. Floyd Brauer.

Accepted for publication 6th May, 1991. thésie rachidienne continue par microtheter peut présenter un risque unique de mauvaise distribution de la solution anesthésique locale et une neurotoxicité locale.

In 1907, the technique of continuous spinal anaesthesia (CSA) was introduced using intermittent injections of amylocaine via a needle which remained in the spinal canal. ${ }^{1}$ This technique was refined in 1944 by threading a ureteral catheter into the lumbar subarachnoid space, ${ }^{2}$ and subsequently has been performed with standard epidural equipment. In an attempt to decrease the complication of post-dural puncture headache following CSA with standard epidural equipment, a microcatheter technique has been developed. ${ }^{3,4}$

Neurological deficits following spinal anaesthesia are rare. ${ }^{5}$ However, cauda equina syndrome following CSA has been reported recently. 6

We report two cases of persistent sacral nerve root deficits following transurethral resection of the prostate (TURP) for benign prostatic hypertrophy. A neurologist was involved in the postoperative care to validate the deficits. In each case, CSA was performed with hyperbaric lidocaine through a lumbar microcatheter.

\section{Case \#1}

A 67-yr-old male with normal coagulation studies and neurological examination was prepared (10\% povidoneiodine solution (Kendall Healthcare)), and a 22-gauge spinal needle was introduced easily into the subarachnoid space $\left(\mathrm{L}_{3-4}\right)$. A 28-gauge CSA catheter (CoSpan ${ }^{(\mathbb{T M}}$, Kendall Healthcare; Mansfield, MA) was inserted (4 cm) without difficulty and its position was verified by the aspiration of cerebrospinal fluid. In the supine position, $0.7 \mathrm{ml}, 5 \%$ lidocaine in $7.5 \%$ dextrose (without epinephrine) was given, and followed by four incremental injections. The total dose before incision was $3.2 \mathrm{ml}$ over $20 \mathrm{~min}$. There was no pain or paraesthesia with needle placement, catheter insertion, or local anaesthetic injection. After surgical incision, another $2.5 \mathrm{ml}$ (three injections) of $5 \%$ lidocaine were administered over ten minutes with the patient in the lithotomy position. Though 
sensation was absent to pin prick about the thighs and perineum, an adequate sensory level could not be obtained and general anaesthesia was required. The duration of surgery was $45 \mathrm{~min}$ and the patient's blood pressure and haemoglobin oxygen saturation were normal throughout. The catheter was removed intact at the end of surgery. On initial examination, the patient's lower extremities were anaesthetic. Within $90 \mathrm{~min}$, there was resolution of motor blockade but the patient described a residual hypaesthetic area on his right inner thigh. On the first postoperative day the patient described bilateral lower extremity weakness and continued decreased sensation of his right thigh. However, he was able to walk with assistance. On the second postoperative day he described an area $(7 \mathrm{~cm}$ diameter) without sensation between the coccyx and anus. Two independent neurological examinations documented decreased rectal tone and sensation $\left(S_{3}\right.$ on the left, $S_{4}$ on the right).

A bone and magnetic resonance imaging scan of the lumbar and sacral spine was noncontributory. The patient was discharged home on the fourth day with a Foley catheter after failing voiding trials. Within one week the lower extremity weakness and paraesthesias about the right inner thigh had completely resolved. However, there was residual rectal incontinence, constipation, and decreased perianal sensation on the left. Three months after surgery and anaesthesia, the patient reported constipation, impotence, and a residual $5 \mathrm{~cm}$ perianal area without sensation. Micturition was normal.

\section{Case \#2}

A 60-yr-old male with normal coagulation studies and neurological examination had a 28-gauge catheter (CoSpan $\left.{ }^{(1 \times)}\right)$ inserted $(2 \mathrm{~cm})$ without difficulty as described in Case \#1. In the supine position, $2.0 \mathrm{ml}$ (three injections) of 5\% lidocaine in $7.5 \%$ dextrose (without epinephrine) were given over $15 \mathrm{~min}$ and a bilateral $T_{11}$ level of analgesia was obtained. There was no pain or paraesthesia with needle placement, catheter insertion, or local anaesthetic injection. Analgesia was adequate for incision. However, $2.3 \mathrm{ml}$ (six injections) of lidocaine was given during the first $30 \mathrm{~min}$ of the procedure and $a T_{10}$ level of sensation was obtained. The duration of surgery was 45 min and the patient's blood pressure and haemoglobin oxygen saturation were normal throughout. The catheter was removed intact at the end of surgery. Within $100 \mathrm{~min}$ the patient had complete recovery of motor and sensory function, except for a hypaesthetic area $(5 \mathrm{~cm}$ diameter) between the coccyx and anus. This sensory deficit persisted throughout the postoperative course. After failing voiding trials he was discharged with a Foley catheter. Nine months after surgery and anaesthesia, the patient reported severe constipation, poor control of flatus, and a residual $5 \mathrm{~cm}$ perianal area with altered sensation. Micturition was normal.

\section{Discussion}

A recent summary reported only 31 cases of neurological deficits in more than 65,000 patients who had received spinal anaesthesia. ${ }^{5}$ The association between neurological sequelae and spinal anaesthesia may have been exaggerated as a number of the cases had pre-existing neurological disease. The contemporary incidence of neurological sequelae with spinal anaesthesia may be even lower as anaesthetic regimens have improved, fewer neurotoxic agents are available, and lower concentrations of local anaesthetics are employed. ${ }^{7}$ The neurological sequelae of spinal anaesthesia have included the "cauda equina syndrome," aseptic meningitis, adhesive arachnoiditis ${ }^{5}$ and isolated nerve root injuries. The cauda equina syndrome after spinal anaesthesia was first reported in $1937^{8-11}$ and is characterized by an onset in the immediate postoperative period of urinary or fecal incontinence, perineal sensory loss, and variable degrees of leg paresis.

The patients in this report had "cauda equina syndrome." Possible causes of the neurological deficits include exacerbation of previous neurological disease, spinal cord ischaemia, infection, positioning, trauma ${ }^{12}$ and direct neurotoxicity due to the local anaesthetic, its diluent, or chemical contaminants. ${ }^{9,13-15}$ On closer analysis, the most plausible explanations include injury to the nerve roots caused by the needle or the spinal catheter, contamination of the anaesthetic solution, and/or a direct neurotoxic effect of the local anaesthetic. The first two explanations are unlikely as there were no paraesthesias on needle placement, catheter insertion, or drug injection, and the local anaesthetic was obtained from stock (5\% lidocaine in $7.5 \%$ dextrose without epinephrine) that was used in other patients without neurologic sequelae. A direct neurotoxic effect of the local anaesthetic may have caused the cauda equina syndrome in these patients.

We postulate that microcatheter CSA may convey a unique risk of local anaesthetic neurotoxicity. In Hurley and Lambert's study ${ }^{4}$ of 58 patients undergoing CSA with a 32-gauge catheter, two cases of inadequate block occurred. They proposed that this was due to "nonuniform distribution of the local anaesthetic owing to the high resistance to injection that is associated with the microcatheter which produces slow rates of flow as the local anaesthetic exits the catheter tip." More recently, Rigler et al. reported four cases of cauda equina syndrome after CSA. ${ }^{6}$ They postulated that maldistribution as well as a high dose of the local anaesthestic resulted in neurotoxic injury. They suggested that the potential for neurotoxicity might be reduced by limiting the distance of catheter 
insertion, using the lowest effective concentration of local anaesthetic, and changing the patient's position and/or the baricity of the local anaesthetic if maldistribution is suspected. In a model of the subarachnoid space, Rigler and Drasner recently demonstrated a sacrally restricted distribution of $5 \%$ lidocaine after single and sequential injections through a sacrally directed 28-gauge subarachnoid microcatheter.*

Hyperbaric 5\% lidocaine with $7.5 \%$ glucose is a short-acting local anaesthetic for spinal anaesthesia and is supplied in the CSA kit. However, a $2 \%$ solution of lidocaine was used by Gordh ${ }^{16}$ when first describing the use of lidocaine for spinal anesthesia in 1948. The 2\% solution provided satisfactory analgesia for perineal procedures and cystoscopy. It was not until 1954 that Berne $^{17}$ introduced the $5 \%$ concentration of lidocaine. The reason for using $5 \%$ lidocaine for spinal anaesthesia is unclear. Some authors have recommended the use of glucose-free $2 \%$ lidocaine for spinal anaesthesia. Kristensen et al.$^{18}$ demonstrated that spinal anaesthesia with glucose-free 2\% lidocaine (isobaric) in doses of 3-4 ml provided satisfactory analgesia for transurethral surgery of the bladder. A comparison of glucose-free $2 \%$ lidocaine $(80 \mathrm{mg})$ or hyperbaric $5 \%$ lidocaine $(80 \mathrm{mg})$ demonstrated that both solutions of lidocaine were reliable for transurological surgery. ${ }^{19}$ Three of the four cases of cauda equina syndrome presented by Rigler $e t a l$. occurred following CSA with a 28 ga catheter and 5\% lidocaine with $7.5 \%$ glucose. In each case there was evidence of a focal sensory block and a large dose of local anaesthetic was required to achieve adequate anaesthesia.

Studies of local anaesthetic neurotoxicity have produced inconsistent results. In rabbits, the intrathecal injection of $8 \%$ or $4 \%$ lidocaine has produced persistent neurological deficits and cauda equina lesions respectively. ${ }^{20}$ Neurological deficits and histological changes have been produced by injecting large doses of $2 \%$ lidocaine intrathecally in sheep. ${ }^{21}$ Structural analysis of rat sciatic nerves after external application of $2 \%$ lidocaine has shown axonal degeneration, Schwann cell damage, and endoneurial oedema. ${ }^{22}$ It has been suggested that neurotoxicity is a general property of local anaesthetics, unique to certain local anaesthetics, or some other property of the vehicle. ${ }^{15,20-26}$ However, neurological deficits are rare following appropriately performed spinal anaesthesia. ${ }^{5}$

Accordingly, CSA may convey a risk of direct local anaesthetic toxicity because large doses of the local anaesthetic were required for adequate anaesthesia. In these cases, the risk may have been increased by

*Presented at the 29th Western Anesthesia Residents Conference, Stanford University Medical Center, April 20, 1991. additional hyperbaric solution administered with the patient in a fixed position.

In summary, we report two cases of sacral nerve root deficits following microcatheter CSA. In both patients, a large volume of $5 \%$ lidocaine $(5.7 \mathrm{ml}$ and $4.3 \mathrm{ml})$ was given over 30 and $45 \mathrm{~min}$ in an attempt to establish and maintain adequate surgical anaesthesia. A possible explanation for the neurological deficits is nonuniform distribution of the anaesthetic solution, which resulted in a neurotoxic dose of the local anaesthetic. If this hypothesis were proved, it may affect clinical decisions regarding CSA.

\section{References}

1 Dean $\mathrm{H}$. Discussion of the relative value of inhalation and injection methods of inducing anaesthesia. BMJ 1907; 5: 869-77.

2 Tuohy $E$. Continuous spinal anesthesia: its usefulness and technique involved. Anesthesiology 1944; 5: 142-8.

3 Drasner K, Connolly M, Reece W. Evaluation of a 28 gauge catheter for continuous spinal anesthesia. Anesth Analg 1990; 70: S88.

4 Hurley R, Lambert D. Continuous spinal anesthesia with a microcatheter technique: preliminary experience. Anesth Analg 1990; 70: 97-102.

5 Kane $R$. Neurologic deficits following epidural or spinal anesthesia. Anesth Analg 1981; 60: 150-61.

6 Rigler M, Drasner K, Krejcie T et al. Cauda equina syndrome after continuous spinal anesthesia. Anesth Analg 1991; 72: 275-81.

7 Greene $N$. Neurological sequelae of spinal anesthesia. Anesthesiology 1961; 22: 682-98.

8 Ferguson $F$, Watkins $K$. Paralysis of the bladder and associated neurological sequelae of spinal anaesthesia. Br J Surg 1937; 25: 735-52.

9 Nicholson $M$, Eversole $U$. Neurological complications of spinal anesthesia. JAMA 1946; 132: 679-85.

10 MacDonald $A$, Watkins $K$. An experimental investigation into the cause of paralysis following spinal anaesthesia. Br J Surg 1938; 25: 879-83.

11 Kennedy F, Effron A, Perry $G$. The grave spinal cord paralysis caused by spinal anesthesia. Surg Gynecol Obstet 1950; 91: 385-98.

12 Vandam $L$, Dripps $R$. Long term follow-up of patients who received 10,098 spinal anesthetics. IV. Neurological disease incident to traumatic lumbar puncture during spinal anesthesia. JAMA 1960; 172: 1483-7.

13 Goldman W, Sandford J. An "epidemic" of chemical meningitis. Am J Med 1960; 29: 94-101.

14 Winkelman $N$. Neurologic symptoms following accidental intraspinal detergent injection. Neurology 1952; 2 : 284-91. 
15 Lundy J, Essex $H$, Kernohan J. Experiments with anesthetics; lesions produced in the spinal cord of dogs by a dose of procaine hydrochloride sufficient to cause permanent and fatal paralysis. JAMA 1933; 101: 1546-50.

16 Gordh $T$. Xylocaine - a new local analgesic. Anaesthesia $1949 ; 4: 4$.

17 Berne S. Spinalanestesi med Xylocain tung 5\%. Svensk Lakartidn 1954; 51 : 1037.

18 Kristensen J, Helbo-Hansen H, Toft P, Hole P. Spinal analgesia with glucose-free $2 \%$ lidocaine. Effect of different volumes. Acta Anaesthesiol Scand 1989; 33: 53-7.

19 Toft P, Bruun-Mogensen C, Kristensen J, Hole P. A comparison of glucose-free $2 \%$ lidocaine and hyperbaric 5\% lidocaine for spinal anaesthesia. Acta Anaesthesiol Scand 1990; 34: 109-13.

20 Ready L, Plumer M, Haschke R, Austin E, Sumi S. Neurotoxicity of intrathecal local anesthetics in rabbits. Anesthesiology 1985; 63: 364-70.

21 Rosen $M$, Baysinger $C$, Shnider $S$ et al. Evaluation of neurotoxicity after subarachnoid injection of large volumes of local anesthetic solution. Anesth Analg 1983; 62: 802-8.

22 Myers $R$, Kalichman $M$, Reisner L, Powell $H$. Neurotoxicity of local anesthetics: altered perineurial permeability, edema, and nerve fiber injury. Anesthesiology 1986; 64: 29-35.

23 Li D, Bahar M, Cole $G$, Rosen $M$. Neurological toxicity of the subarachnoid infusion of bupivacaine, lignocaine or 2-chloroprocaine in the rat. Br J Anaesth 1985; 57: 424-9.

24 Barsa J, Batra M, Fink B, Sumi S. A comparative in vivo study of local neurotoxicity of lidocaine, bupivacaine, 2-chloroprocaine, and a mixture of 2-chloroprocaine and bupivacaine. Anesth Analg 1982; 61: 961-7.

25 Fink B, Kennedy R, Hendrickson A, Middaugh M. Lidocaine inhibition of rapid axonal transport. Anethesiology 1972; 36: 422-32.

26 Gissen A, Datta $S$, Lambert $D$. The chloroprocaine controversy II. Is chloroprocaine neurotoxic? Regional Anesthesia 1984; 9: 135-45. 